\title{
Fucoidan inhibits parainfluenza virus type 2 infection to $\mathrm{LLCMK}_{2}$ cells
}

\author{
Naomi Taoda ${ }^{1}$, Eri Shinsi ${ }^{1}$, Kumiko Nishis ${ }^{1}$, Saori Nishioka ${ }^{1}$, Yukari Yonezawa ${ }^{1}$, Jun Uematsu ${ }^{1}$, Emi Hattori, \\ Hidetaka Yamamoto', Mitsuo Kawano ${ }^{2}$, Masato Tsurudome ${ }^{2}$, Myles O’Brien ${ }^{3}$, Tetsuro Yamashita ${ }^{4}$ and \\ Hiroshi KOMADA, ${ }^{1,5}$ \\ ${ }^{1}$ Department of Microbiology, Suzuka University of Medical Science, Suzuka, Mie 510-0293; ${ }^{2}$ Department of Microbiology, Mie Uni- \\ versity Graduate School of Medicine, Tsu, Mie 514-8507; ${ }^{3}$ Graduate School of Mie Prefectural College of Nursing, Tsu, Mie 514-0116; \\ ${ }^{4}$ Miyako Kagaku Co.Ltd., Chiyoda-Ku, Tokyo 100-0005; and ${ }^{5}$ Department of Microbiology, Graduate School of Clinical Nutrition, Su- \\ zuka University of Medical Science, Suzuka, Mie 510-0293, Japan
}

(Received 11 August 2008; and accepted 8 September 2008)

\begin{abstract}
The effects of fucoidan and L-fucose, a fundamental major component of fucoidan, on the growth of human parainfluenza virus type 2 (hPIV-2) in LLCMK $_{2}$ cells were investigated. Fucoidan inhibited cell fusion and hemadsorption, but L-fucose only partly inhibited both. Virus RNA was not detected in the hPIV-2 infected cells cultured with fucoidan. However, L-fucose did not inhibit virus RNA synthesis. Indirect immunofluorescence study showed that virus protein synthesis was inhibited by fucoidan, but not by L-fucose. Furthermore, using a recombinant, green fluorescence protein-expressing hPIV-2, it was found that virus entry was inhibited by fucoidan, but not by L-fucose. These results suggested that fucoidan inhibited virus adsorption to the surface of the cells by binding to the cell surface and prevented infection, indicating that the sulfated polysaccharide form was important for the inhibition by fucoidan.
\end{abstract}

The inhibitory effect of sulfated polysaccharides, including fucoidan, on the replication of enveloped viruses such as herpes simplex virus, human cytomegalovirus, vesicular stomatitis virus (VSV), Sindbis virus and human immunodeficiency virus (HIV) was reported by Baba et al. (1). The mechanism of the inhibitory action of these compounds has been attributed to the inhibition of virus adsorption to the cells. Fucoidan is a sulfated polysaccharide and is extracted from the brown alga Okinawa mozuku Cladosiphon okamuranus and is effective in controlling white spot syndrome in kuruma shrimp, Penaeus japonicus (8).

Human parainfluenza virus type 2 (hPIV-2) is one

The first two authors equally contributed to the work. Address correspondence to: Prof. Hiroshi Komada Department of Microbiology, Graduate School of Clinical Nutrition, Suzuka University of Medical Science, 1001-1 Kishioka, Suzuka, Mie 510-0293, Japan Tel: +81-59-383-8991, Fax: +81-59-383-9666 E-mail: komada@suzuka-u.ac.jp of the major human respiratory tract pathogens of infants and children. hPIV-2 is a member of the genus Rubulavirus in the family Paramyxoviridae, and it possess a single-stranded nonsegmented and negative stranded RNA genome of approximately $15 \mathrm{k}$ bases. The gene order of hPIV-2 is 3'-(leader)NP-V/P-M-F-HN-L-(trailer)-5'. All genes of hPIV-2 were sequenced by our group $(2-6,10)$, monoclonal antibodies (mAbs) were made by Tsurudome et al. (9), and the infectious hPIV-2 from cDNA clone was constructed by Kawano et al. (7).

In the present study, we investigated the effect of fucoidan on the replication of hPIV-2 in LLCMK $_{2}$ cells. Virus RNA was prepared and amplified by polymerase chain reaction (PCR). Virus protein expression was observed by indirect immunofluorescence study using mAbs against NP, F and HN proteins of hPIV-2. The inhibitory effect of fucoidan on the entry of hPIV-2 into LLCMK ${ }_{2}$ cells was analyzed using a recombinant, green fluorescence protein (GFP)-expressing hPIV-2 (rghPIV-2).

Fucoidan (more than $80 \%$ pure: Miyako Kagaku, 
Table 1 Primers for $C D N A$ synthesis and PCR

\begin{tabular}{|c|c|c|}
\hline & Forward & Reverse \\
\hline \multirow{2}{*}{ NP } & ATTTTCTGGGGAACTCCAGA & GTCTAGTTTGATTTGTCTGG \\
\hline & $(1021-1040)$ & $(1861-1880)$ \\
\hline \multirow{2}{*}{$\mathrm{F}$} & CCCTATCCCTGAATCACAAT & TGTCACGAGACGTTACGACA \\
\hline & $(5821-5840)$ & $(6661-6680)$ \\
\hline \multirow{2}{*}{$\mathrm{HN}$} & ATTTCCTGTATATGGTGGTC & GAACTCCCCTAAAAGAGATG \\
\hline & $(7741-7760)$ & $(8481-8500)$ \\
\hline
\end{tabular}

The figures show nucleotide number in all hPIV-2 genes.

Tokyo, Japan) was dissolved at $100 \mathrm{mg} / \mathrm{mL}$ in $10 \mathrm{mM}$ phosphate buffered saline, $\mathrm{pH} 7.2$ (PBS). After sterilization by autoclaving, it was centrifuged at $2500 \mathrm{rpm} 10 \mathrm{~min}$, and a small amount of insoluble materials were discarded. L-fucose (Nakarai Chemicals, Osaka, Japan) was dissolved at $200 \mathrm{mg} / \mathrm{mL}$ in PBS and sterilized by filtration.

Human parainfluenza virus type 2 (hPIV-2) (Toshiba strain) was used. rghPIV-2 was constructed by the method reported by Kawano et al. (7). There was no significant difference in the replication of the rghPIV-2 compared to that of hPIV-2 (data not shown). LLCMK $_{2}$ cells (rhesus monkey kidney cell line) were cultured in a flat-bottomed 24-well plate in $1 \mathrm{~mL}$ culture medium. Minimum essential medium $\alpha(\mathrm{MEM} \alpha)$ (Wako, Osaka, Japan) supplemented with $2 \%$ fetal calf serum (FCS) and $0.1 \mathrm{mg} / \mathrm{mL} \mathrm{ka-}$ namycin was used. The cells were cultured at $37^{\circ} \mathrm{C}$ in a humidified atmosphere with $5 \% \mathrm{CO}_{2}$. When the cells became confluent $\left(5 \times 10^{5}\right.$ cells $)$, the medium was changed to MEM $\alpha$ with $0.5 \%$ FCS and $0.1 \mathrm{mg} /$ $\mathrm{mL}$ kanamycin, fucoidan or L-fucose was added to the cells, and they were infected with hPIV-2 (300 $\left.\mathrm{TCID}_{50}\right)$. The cell fusion and hemadsorption (Had) were observed at 4 day post infection. Had test was carried out using sheep red blood cells (SRBC). The cells were incubated with $0.4 \% \mathrm{SRBC}$ at room temperature for $30 \mathrm{~min}$, washed 4 times with PBS, and Had was observed under a light microscope for cell culture. RNA was extracted from the cells $\left(2 \times 10^{6}\right.$ cells) cultured in a flat-bottomed 6 -well plate using TRIZOL reagent (Invitrogen, CA, USA) according to the manufacturer's method. cDNA was synthesized with $4 \mu \mathrm{g}$ of RNA using superscript II reverse transcriptase (Invitrogen) with forward primers for NP, F and HN genes of hPIV-2 (Table 1). PCR was done with cDNA using forward and reverse primers for NP, F and HN genes (Table 1) and Ex Taq (Takara, Shiga, Japan).

The immunofluorescence study was performed as follows. The cells were fixed with $10 \%$ formalde-

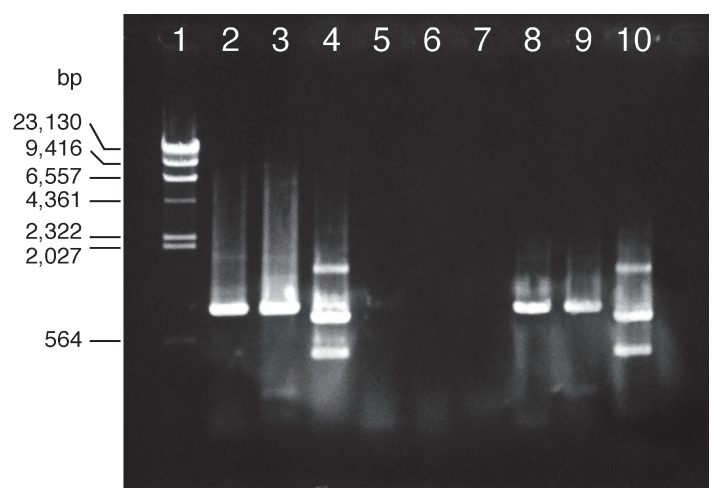

Fig. 1 Fucoidan inhibited RNA synthesis of hPIV-2, but L-fucose did not inhibit. Lane 1: marker (base pair); lanes 2 , 3 , and $4: \mathrm{NP}, \mathrm{F}$ and $\mathrm{HN}$ of hPIV-2, respectively; lanes 5, 6, and $7: \mathrm{NP}, \mathrm{F}$ and $\mathrm{HN}$ of hPIV-2 added with fucoidan; lanes 8, 9, and 10: NP, F and HN of hPIV-2 added with L-fucose.

hyde-PBS at room temperature for $15 \mathrm{~min}$, washed with PBS, and incubated with mouse mAbs against $\mathrm{NP}, \mathrm{F}$ and $\mathrm{HN}$ proteins of hPIV-2 at room temperature for $30 \mathrm{~min}$. After washing with PBS, the cells were incubated with Alexa 488 conjugated second antibody to mouse IgGs (Invitrogen) at room temperature for $30 \mathrm{~min}$. The cells were observed under a fluorescence microscope (Olympus, Tokyo, Japan).

Fucoidan ( $300 \mu \mathrm{L}$ : equivalent to $30 \mathrm{mg})$ completely inhibited both cell fusion and Had (data not shown). A lot of cell fusion and Had were observed in hPIV-2 infected cells with $20 \mathrm{mg}$ L-fucose (data not shown). Even high doses of L-fucose $(40 \mathrm{mg}$ and $60 \mathrm{mg}$ ) did not completely inhibit both cell fusion and Had (data not shown): a little fusion and Had were observed dose-independently. Fucoidan and L-fucose did not disturb normal cell morphology at the concentrations used in the experiments.

Virus RNA synthesis of the cells cultured with fucoidan or L-fucose was analyzed. As shown in Fig. 1, fucoidan completely inhibited RNA synthesis. No NP, F nor HN gene of hPIV-2 was detected in the hPIV-2 infected cells cultured with fucoidan. 

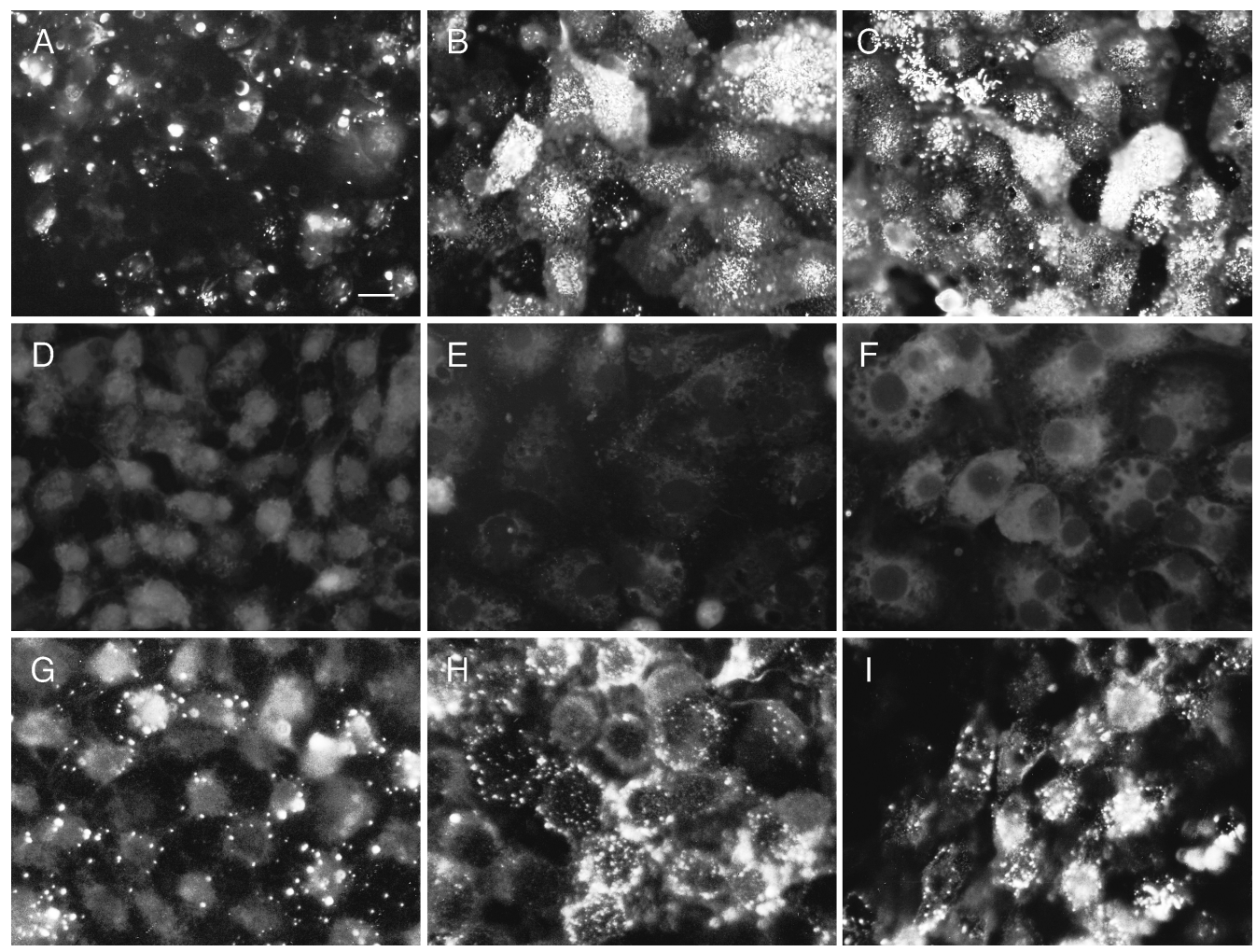

Fig. 2 Effect of fucoidan and L-fucose on the expression of NP, F and HN proteins of hPIV-2. The expression of NP (A), F (B) and HN (C) proteins of hPIV-2 infected cells. Fucoidan inhibited completely the expression of NP (D), F (E) and HN (F) proteins. L-fucose did not inhibit the expression of NP (G), $F(H)$ and $H N(I)$ proteins. Bar $25 \mu \mathrm{m}$
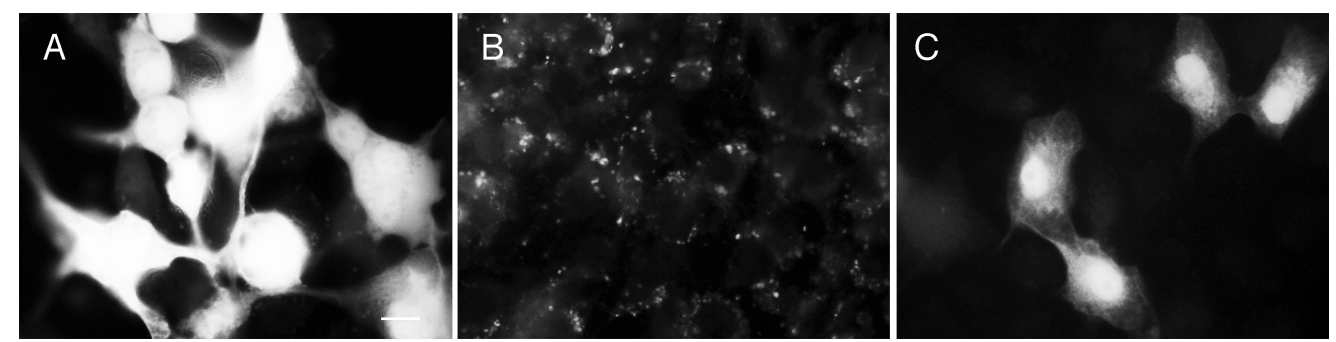

Fig. 3 Fucoidan inhibited the entry of rghPIV-2, but L-fucose did not. Cells infected with rghPIV-2 (A), cells infected with rghPIV-2 cultured with fucoidan (B), and cells infected with rghPIV-2 with L-fucose (C). Bar $25 \mu \mathrm{m}$

However, L-fucose did not inhibit virus RNA synthesis: NP, F and $\mathrm{HN}$ genes were detected just the same as in hPIV-2 infected positive controls (Fig. 1).

Indirect immunofluorescence study was performed to investigate the effects of fucoidan $(300 \mu \mathrm{L})$ and L-fucose $(60 \mathrm{mg})$ on $\mathrm{hPIV}-2$ protein expression. LL$\mathrm{CMK}_{2}$ cells were cultured with fucoidan or L-fucose, and were infected with hPIV-2. At 4 day post infection, the cells were fixed and stained with the mAbs against NP, F and HN proteins of hPIV-2. Figs. 2A, $\mathrm{B}$ and $\mathrm{C}$ show the NP, F and $\mathrm{HN}$ protein expression in hPIV-2 infected cells, respectively. In hPIV-2 in- fected cells, NP, F and HN proteins were clearly observed in almost all the cells. Fucoidan completely inhibited the expression of NP (Fig. 2D), F (Fig. 2E), and $\mathrm{HN}$ (Fig. 2F) proteins. However, L-fucose only partly inhibited protein expression: NP, F and HN proteins were still clearly observed in a lot of cells, though the intensity was a little weaker than that of hPIV-2 infected cells (Figs. 2 G, H, and I, respectively).

These results suggested that fucoidan inhibited the entry of hPIV-2 into cells by binding to the cell surface. To confirm this possibility, rghPIV-2 was 
used. Fucoidan or L-fucose was added to the cell culture, the cells were infected with rghPIV-2 $(6 \times$ $\left.10^{5} \mathrm{TCID}_{50}\right)$ and cultured for $24 \mathrm{~h}$. The cells were fixed with $3.3 \%$ formaldehyde-PBS and observed under a fluorescence microscope. As shown in Fig. 3A, the cells infected with rghPIV-2 had strong fluorescence. In the samples cultured with fucoidan, no cells had fluorescence of GFP (Fig. 3B), indicating that fucoidan inhibited the entry of rghPIV-2 into cells. However, in the rghPIV-2 infected samples cultured with L-fucose, some cells had strong fluorescence (Fig. 3C), indicating that L-fucose could not inhibit the entry of rghPIV-2 into cells.

The effect of fucoidan, one of the sulfated polysaccharides, on hPIV-2 infection was analyzed in the present study, and we showed that it had an inhibitory effect. Virus RNA and protein syntheses were completely inhibited by fucoidan. In addition, it was indicated that fucoidan inhibited the entry of hPIV-2. Fucoidan is a large polymer of sulfated fucose. The effect of L-fucose, a monosaccharide, on hPIV-2 replication was analyzed. L-fucose partly inhibited cell fusion, Had and virus protein synthesis. However, L-fucose did not inhibit either virus RNA synthesis or virus entry into cells. These results indicated that the sulfated polymer form is important for the inhibitory effect of fucoidan.

Baba et al. reported that sulfated polysaccharides inhibited the growth of various enveloped viruses such as herpes simplex virus, VSV and HIV (1). They also showed that sulfated polysaccharides, including fucoidan, did not inhibit replication of parainfluenza virus type 3 (hPIV-3). However, in the present investigation, fucoidan inhibited replication of hPIV-2. The homology between structural proteins of hPIV-2 and those of hPIV-3 is not so high $(2-6,10)$. They belong to different genera, and hPIV-2 and hPIV-3 might use different molecules of the cell surface as receptors. It was also indicated by Takahashi et al. (8) that fucoidan inhibited the attachment of white spot syndrome virus to the cells, resulting in prevention of virus infection in kuruma shrimp. Our data are consistent with their results: it was shown that, using rghPIV-2, fucoidan could inhibit the entry of the virus into cells. Hemagglutination (HA) test of fucoidan was carried out and the result that fucoidan had HA activity (data not shown) supported the possibility that it could bind to the surface of the cells and prevent virus at- tachment to the cells.

\section{REFERENCES}

1. Baba M, Snoeck R, Fauwels R and Clercq ED (1988) Sulfated polysaccharides are potent and selective inhibitors of various enveloped viruses, including herpes simplex virus, cytomegalovirus, vesicular stomatitis virus, and human immunodeficiency virus. Antimicrob Agents Chemother 32, 1742-1745.

2. Ohgimoto S, Bando H, Kawano M, Okamoto K, Kondo K, Tsurudome M, Nishio M and Ito Y (1990) Sequence analysis of $\mathrm{P}$ gene of human parainfluenza type 2 virus; $\mathrm{P}$ and cystein-rich proteins are translated by two mRNAs that differ by two non-templated G residues. Virology 177, 116-123.

3. Kawano M, Bando H, Yuasa T, Kondo K, Tsurudome M, Komada H, Nishio M and Ito Y (1990) Sequence determination of the hemagglutinin-neuraminidase $(\mathrm{HN})$ gene of human parainfluenza type 2 virus and the construction of a phylogenetic tree for $\mathrm{HN}$ proteins of all the paramyxoviruses that are infectious to humans. Virology 174, 308-313.

4. Kawano M, Bando H, Ohgimoto S, Kondo K, Tsurudome M, Nishio M and Ito Y (1990) Sequence of the fusion protein gene of human parainfluenza type 2 virus and its 3' intergenic region: lack of small hydrophobic $(\mathrm{SH})$ gene. Virology 178, 289-292.

5. Kawano M, Bando H, Ohgimoto S, Okamoto K, Kondo K, Tsurudome M, Nishio M and Ito Y (1990) Complete nucleotide sequence of the matrix gene of human parainfluenza type 2 virus and expression of the $\mathrm{M}$ protein in bacteria. $\mathrm{Vi}$ rology 179, 857-861.

6. Kawano M, Okamoto K, Bando H, Kondo K, Tsurudome M, Komada H, Nishio M and Ito Y (1991) Characterizations of the human parainfluenza type 2 virus gene encoding the $\mathrm{L}$ protein and the intergenic sequences. Nucleic Acids Res 19, 2739-2746

7. Kawano M, Kaito M, Kozuka Y, Komada H, Noda N, Nanba K, Tsurudome M, Ito M, Nishio M and Ito Y (2001) Recovery of infectious human parainfluenza type 2 virus from cDNA clones and properties of the defective virus without V-specific cysteine-rich domain. Virology 284, 99-112.

8. Takahashi Y, Uehara K, Watanabe R, Okumura T, Yamashita T, Omura H, Yomo T, Kawano T, Kanemitsu A, Narasaka H, Suzuki N and Itami T (1998) Efficacy of oral administration of fucoidan, a sulfated polysaccharide, in controlling white spot syndrome in kuruma shrimp in Japan. In: Advances in Shrimp Biotechnology (Flegel TW, ed.), pp.171-173, The National Center for Genetic Engineering and Biotechnology, Thailand.

9. Tsurudome M, Nishio M, Komada H, Bando $\mathrm{H}$ and Ito $\mathrm{Y}$ (1989) Extensive antigenic diversity among human parainfluenza type 2 virus isolates and immunological relationships among paramxoviruses revealed by monoclonal antibodies. Virology 171, 38-48.

10. Yuasa T, Bando H, Kawano M, Tsurudome M, Nishio M, Kondo K, Komada H and Ito Y (1990) Sequence analysis of the 3' gemome end and NP gene of human parainfluenza type 2 virus: sequence variation of the gene-starting signal and the conserved 3' end. Virology 179, 777-784. 